\title{
CONTÁTIL: UMA TECNOLOGIA ASSISTIVA AO ENSINO DE FUNDAMENTOS MATEMÁTICOS
}

\author{
Cleiton Moreira Marques, ULBRA, cmormarques@gmail.com \\ Maria Adelina Raupp Sganzerla, PPGECIM, ULBRA, masganzerla@gmail.com \\ Marlise Geller, PPGECIM, ULBRA, marlise.geller@gmail.com
}

Resumo: Este artigo é um recorte da monografia de conclusão de curso em Ciência da Computação, descrevendo a construção de uma Tecnologia Assistiva (TA), para auxiliar no ensino da Matemática para deficientes visuais. Para que este objetivo se tornasse possível, foram realizados estudos sobre a deficiência visual, bem como as dificuldades enfrentadas na rotina de alfabetização Matemática para crianças videntes, com baixa visão e com ausência total da visão, conhecendo tal rotina, ferramentas disponíveis, e técnicas utilizadas por professores especializados em educação inclusiva. O dispositivo desenvolvido possui como inspiração principal o Material Dourado, constituindo-se uma readaptação para uma ferramenta automatizada. Assim, surgiu a "Contátil" (Contar + Tátil), capaz de representar valores numéricos, de forma tátil e audível. Sua validação foi efetivada com um grupo de 19 professores que ensinam matemática, na qual foi possível constatar o potencial da TA.

Palavras-chave: Material Dourado; Tecnologia Assistiva; Sistema Embarcado; Ensino de Matemática.

Abstract: This paper is a clipping of completion of coursework in Computer Science, describing the construction of an Assistive Technology (AT), to assist in the teaching of mathematics for the visually impaired. In order to make this goal possible, studies on visual impairment and the difficulties faced in the routine of literacy and teaching of mathematics for sighted children, with low vision and with total absence of vision were carried out, knowing the routine, available tools, and techniques used by teachers specializing in special education. The device glimpsed has as its main inspiration the Gold Material, a retrofit for an automated tool could be made. Thus, the "Contátil" (Count + Tactile) appeared, able to represent numeric values, tactile and audible. Its validation was carried out with a group of 19 teachers who teach mathematics, in which it was possible to verify the potential of AT.

Keywords: Gold Material; Assistive Technology; Embedded System; Software; mathematics.

\section{INTRODUÇÃO}

O aprendizado da matemática sempre representou um desafio para alunos das mais variadas faixas etárias. Segundo Nunes e Lomônaco (2010) em se tratando de crianças com deficiência este obstáculo torna-se ainda maior pela carência de métodos, processos e equipamentos que facilitem esse contato com os números. Este trabalho apresenta uma tecnologia com o intuito de melhorar a curva de aprendizado da Matemática básica de alunos com deficiência visual.

Tecnologia Assistiva - TA é um termo genérico usado para descrever não somente elementos que necessariamente envolvam algum tipo de automação, robótica, tecnologia digital ou mesmo, estar inserido no contexto da informática. Um simples apoio para auxiliar um indivíduo com dificuldade motora a segurar um talher, por exemplo, enquadra-se dentro da definição de TA. Para Bersch e Machado (2007), "consistem em um arsenal de recursos e serviços que contribuem para proporcionar ou ampliar habilidades funcionais de pessoas com deficiência e, consequentemente, promover vida independente e inclusão". 
Frente às necessidades expostas, juntamente com o grupo de pesquisa LEI (Laboratório de Estudos de Inclusão), aprovado pelo Edital $^{1}$, idealizou-se esse projeto, que consiste em desenvolver uma TA que unisse fundamentos de computação, engenharia eletrônica e mecânica, bem como conceitos educacionais, reunidos em um dispositivo que pudesse intermediar de maneira simples, porém eficaz, o ensino da matemática básica para alunos deficientes visuais, por meio dos sentidos que lhes são remanescentes. Para Silva, Campos e Sá (2007), as informações tátil, auditiva, sinestésica e olfativa são melhor desenvolvidas pelas pessoas cegas, porque elas recorrem a esses sentidos com mais frequência para decodificar e armazenar na memória as informações.

Como forma de evidenciar a eficácia da TA desenvolvida, um grupo de 19 professores que ensinam Matemática foram convidados a participar das etapas de validação da Contátil, todos com experiência na área de ensino especial, alguns possuindo inclusive deficiência visual. A equipe teve a missão de avaliar a Contátil em diferentes aspectos como usabilidade, e didática, colocando-se na perspectiva do próprio aluno cego.

\section{DEFICIÊNCIA VISUAL E INCLUSÃO MATEMÁTICA}

A Deficiência Visual é definida como a perda total ou parcial, congênita ou adquirida, da visão. Há várias classificações disponíveis, que variam conforme as limitações e os fins que se destinam.

É considerado cego ou de visão subnormal (baixa visão) aquele que apresenta desde ausência total da visão até alguma percepção luminosa que possa determinar formas a curtíssima distância. Segundo Conde (2005), na medicina duas escalas oftalmológicas ajudam a estabelecer a existência de grupamentos de deficiências visuais: a acuidade visual, ou seja, aquilo que se enxerga a determinada distância e o campo visual que designa a amplitude da área alcançada pela visão. O termo deficiência visual não significa, necessariamente, total incapacidade para ver.

É importante ressaltar que a inclusão no âmbito educacional possui papel decisivo para a transformação na maneira de viver e aprender novos conceitos, uma vez que proporciona às pessoas com deficiência, estímulos para a obtenção de novos conceitos e práticas.

Para Sganzerla (2014), a inclusão é muito mais que uma simples matrícula garantida na rede escolar, um cumprimento da Lei, uma oportunidade de estar junto a outras crianças da mesma idade, de compartilhar brincadeiras e aprendizados no mesmo ambiente. Mas sim, oportunizar uma educação com qualidade, com profissionais capacitados e com os recursos didáticos necessários para o seu desenvolvimento tanto intelectual como social.

Assim, tais fatores devem ser levados em consideração durante o processo de aprendizado nas escolas. Situações aparentemente simples, como a percepção espacial da sala de aula, pátio e refeitório, que se dá automaticamente para o aluno vidente, só é possível ao aluno cego por um processo de reconhecimento, através da exploração, do toque, da audição e da convivência no ambiente. É importante que o educador tenha consciência da importância desses fatos para que a criança com deficiência possa sentir-se à vontade no ambiente escolar, tanto quanto a vidente, e assim obter o máximo rendimento em seu desempenho. Libâneo (2007) afirma que: "o grande objetivo das escolas é a aprendizagem dos alunos, e a organização escolar necessária é a que leva a melhorar a qualidade dessa aprendizagem".

O Material Dourado Montessori destina-se a atividades que auxiliam o ensino e a aprendizagem do sistema de numeração decimal-posicional e dos métodos para efetuar as operações matemáticas fundamentais, sendo uma ferramenta simples e altamente didática, foi criada pela médica e educadora italiana Maria Montessori.

${ }^{1}$ Edital UNIVERSAL-MCTI/CNPq No $14 / 2013$ 
Com o Material Dourado as relações numéricas abstratas passam a ter uma imagem concreta, facilitando a compreensão. Obtém-se, então, além da compreensão dos algoritmos, um notável desenvolvimento do raciocínio e um aprendizado mais agradável.

A Figura 1 ilustra as peças que compõem o Material Dourado, sendo que suas representações de grandezas matemáticas equivalem a: um cubinho (Figura 1d) 1 unidade; uma barra (Figura 1c) equivale a 10 cubinhos, ou seja, 1 dezena ou 10 unidades; uma placa (Figura 1b) equivale a 10 barras ou 100 cubinhos (1 centena, 10 dezenas ou 100 unidades); um cubo (Figura 1a) equivale a 10 placas ou 100 barras ou 1000 cubinhos (1 unidade de milhar,10 centenas, 100 dezenas ou 1000 unidades).

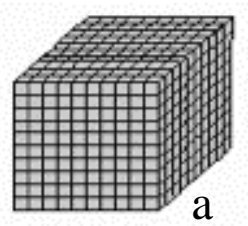

cubo

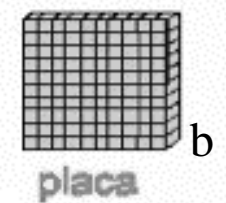

Figura 1 - Componentes do Material Dourado.

Fonte: http://www.utfpr.edu.br/cornelioprocopio/cursos/licenciaturas/Ofertadosneste-Campus/matematica/laboratorios/material-didatico/material-dourado

Existe ainda, uma latente carência de metodologias que apoiem o projeto e desenvolvimento de sistemas educativos, tal carência se mostra ainda maior quando se agrega o fato de que o objeto educativo em questão, faz parte de um contexto envolvendo uma Tecnologia Assistiva. Visando suprir esta lacuna, está sendo implementado, como forma de Trabalho de conclusão da Especialização em Engenharia de Software de um dos membros da equipe de estudos de inclusão, um Modelo que visa auxiliar o desenvolvimento de projetos de Tecnologias Assistivas Educativas, chamado Assistive Thinking, espera-se ainda, que uma nova versão da Contátil seja desenvolvida fazendo uso deste modelo.

\section{DINÂMICA E IMPLEMENTAÇÃO DA CONTÁTIL}

A Contátil é, resumidamente, a automatização do Material Dourado, de forma a permitir que uma pessoa com deficiência visual possa interagir com suas peças de forma tátil. Conta com um menu de opções com quatro modos diferenciados: "Aprendizado dos números", "Calculadora Tátil", "Calculadora Interativa Tátil" e "Atividades", após escolhido o modo de funcionamento e inseridas as entradas numéricas o retorno para o usuário é efetuado pelo meio físico, em forma de áudio e de blocos táteis (SGANZERLA, 2014; MARQUES, 2015).

O desenvolvimento de um equipamento de cunho educacional tende a ser um grande desafio, visto que elementos multidisciplinares e a estrutura da dinâmica de interação usuário/dispositivo devem ser levados em consideração no decorrer de todo o projeto. Para Tesseroli e Tuyarot (2016), um objeto de aprendizagem é uma construção realizada com um sentido e objetivo pré-determinado que é utilizar o mesmo como uma ferramenta para transmitir um conhecimento. Na sequência, serão apresentados os quatro modos de operação da Contátil:

Ao selecionar o modo "Aprendizado dos Números", é solicitada ao usuário a entrada de um número decimal inteiro, o valor deverá ser entre 1 e 999, sendo o último o valor máximo possível que a Contátil pode representar em unidade, dezena e centena.

Ao digitar um valor, este será informado de forma audível ao usuário, e em seguida haverá a movimentação dos blocos para que também esteja representado de forma tátil, estando a representação disponível ao usuário enquanto a tecla "Enter" não for pressionada. Uma vez que isso ocorra, os blocos descerão zerando a simbologia dos blocos e deixando o equipamento 
disponível para uma nova interação. A Figura 2 ilustra a Contátil representando o número 24 (nenhuma centena, duas dezenas e quatro unidades).

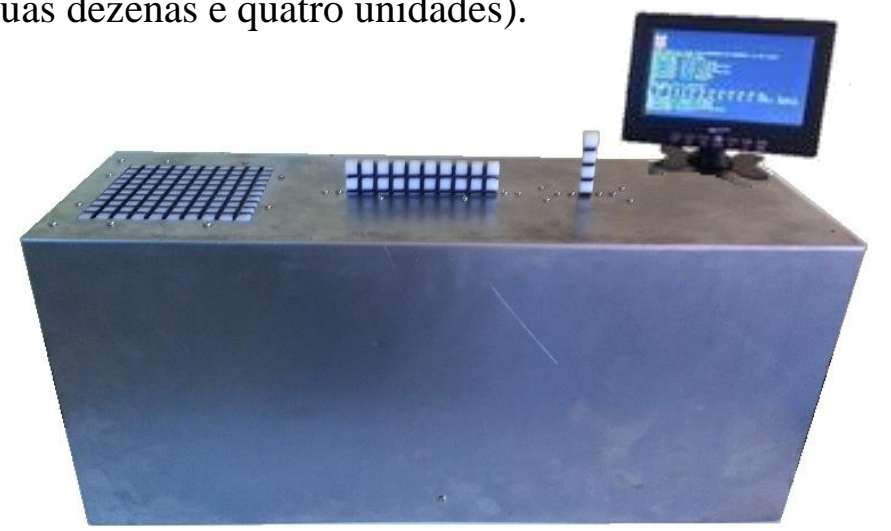

Figura 2 - Representação do valor 24

Fonte: A pesquisa.

$\mathrm{Na}$ "Calculadora Interativa Tátil" espera-se que o usuário entre com os valores e a operação. Ao digitar o valor da primeira parcela, este será informado de forma audível ao usuário, e em seguida haverá a movimentação dos blocos até que esteja representado de forma tátil, ao pressionar a tecla "Enter", os blocos novamente descerão, neste momento será solicitada a operação matemática a ser realizada (adição, subtração, multiplicação e divisão) a mesma será informada audivelmente ao usuário. Em seguida será solicitada a segunda parcela, que, da mesma forma, será informada de forma audível e tátil. Ao pressionar a tecla "Enter", será então apresentado o resultado de forma tátil. Assim, o usuário poderá comparar as parcelas ao seu resultado. A "Calculadora Tátil" difere da anterior somente pelo fato de que as representações intermediárias dos valores não são realizadas, ou seja, somente o resultado final é tátil.

No modo "Atividades" a Contátil irá apresentar atividades em forma de perguntas referentes a valores e grandezas matemáticas que possuem como resposta um determinado número, neste momento deverá ser digitado no teclado o valor numérico correspondente à resposta. Em caso de acerto será emitida uma mensagem de congratulação, em caso de erro será emitida uma mensagem de incentivo para que seja tentado novamente em uma próxima vez, e informado o valor correto. Em seguida a máquina irá acionar os blocos representativos de acordo com a resposta e aguardará que a tecla "Enter" seja pressionada para voltar ao estado inicial. A seguir, um breve relato dos detalhes técnicos que permearam a construção da Contátil.

O Raspberry Pi é um microcomputador de reduzidas dimensões (do tamanho de um cartão de crédito), desenvolvido pela Raspberry Pi Foundation é o mais popular do segmento, baseado num SOC (system on chip) BCM2835 que se encontra em muitos smartphones do mercado. Este SoC integra um processador (CPU) do tipo ARM com frequência de trabalho de 700Mhz, uma unidade de processamento gráfico (GPU) e uma memória RAM de 512MB partilhada com o chip gráfico, (RICHARDSON e WALLACE, 2013).

Na Contátil foi utilizada a Raspberry PI modelo B, sendo que a mesma não possui uma memória do tipo Flash, este tipo de memória é capaz de armazenar dados de forma não volátil (persistentes mesmo sem alimentação elétrica). Usualmente sistemas embarcados utilizam este tipo de memória para ter os componentes de software gravados, sendo assim, fez se necessário o uso de um cartão de memória com encapsulamento do tipo SD, neste cartão foram gravados os componentes do Sistema Operacional, o bootloader e o kernel do Linux.

Além da Raspberry, uma MCU (Micro Controller Unit), também foi utilizada nesta implementação, a aplicação desta consiste no controle dos motores de passos que movimentam os blocos das centenas, dezenas e unidades. Para que este controle fosse possível, foi utilizado 
um microcontrolador da NXP, o LPC1768, um microcontrolador ARM Córtex M3 com uma excelente configuração, considerando seu uso para sistemas embarcados, opera a $100 \mathrm{MHz}$, e possui 512MB de memória Flash e 64KB de memória RAM.

O módulo de UART foi utilizado para comunicação serial, além disso, Timers com configuração de atuação física em saídas digitais do microcontrolador, assim, gerando uma frequência controlada de pulsos elétricos, responsáveis pelo acionamento dos motores de passos. Através da configuração realizada, foi possível controlar a velocidade de acionamento dos motores, bem como, selecionar a direção de giro e também a quantidade de pulsos enviados para os motores, controlando assim os pontos de parada segundo os valores a serem representados.

Os motores de passo são usados em aplicações de serviço relativamente leves, o seu funcionamento básico é dado pelo uso de solenoides alinhados dois a dois que quando energizados atraem o rotor fazendo-o se alinhar com o eixo determinado pelos solenoides, causando assim uma pequena variação de ângulo que é chamada de passo. A velocidade e o sentido de movimento são determinados pela forma como cada solenoide é ativado (sua ordem e a velocidade entre cada ativação). Para ser acionado, um motor de passo de imã permanente como o SM7.5-A05NC, utilizado no projeto da Contátil, é necessário que suas bobinas sejam acionadas em sequência movimentando o eixo através de pequenos passos de $7.5^{\circ}$, a frequência aplicada é a variável que afeta a velocidade de giro do motor.

O projeto da mecânica da Contátil foi inspirado a partir da observação do funcionamento de sistemas de movimentação por fuso do tipo "sem fim", largamente usado para movimentar portões automatizados do tipo "basculante". Este tipo de movimentação possui um fuso com rosca trapezoidal, acoplado ao eixo do motor responsável pela movimentação do sistema para ambas as direções, (para cima e para baixo) coordenadas pelo sentido de giro do motor e por uma peça com rosca interna que fique fixa na parte a ser movimentada. A aplicação deste conceito no equipamento consiste em que a cada inserção de um valor numérico pelo usuário no sistema, ocorram movimentações das peças que representam valores numéricos. Essas peças devem subir até determinado ponto controlado eletronicamente e, após o comando do usuário, descer novamente para a posição de repouso encontrando uma chave de fim de curso.

Os blocos das unidades, dezenas e centenas foram fabricados com polietileno, um polímero com maciez suficiente para ser usinado com facilidade, porém não demasiadamente frágil, sendo assim, capaz de suportar as movimentações, toque dos usuários e até possíveis travamentos mecânicos advindos dos testes de desenvolvimento, as peças foram feitas em máquinas de fresa tendo ranhuras com a espessura de $3 \mathrm{~mm}$, sendo esta medida suficiente para a percepção tátil. Além das ranhuras, como sugestão após os testes realizados, as ranhuras foram pintadas (Figura 3), de forma a facilitar a visualização dos valores representados por alunos que possuam algum percentual de visão, chamados de baixa visão. 


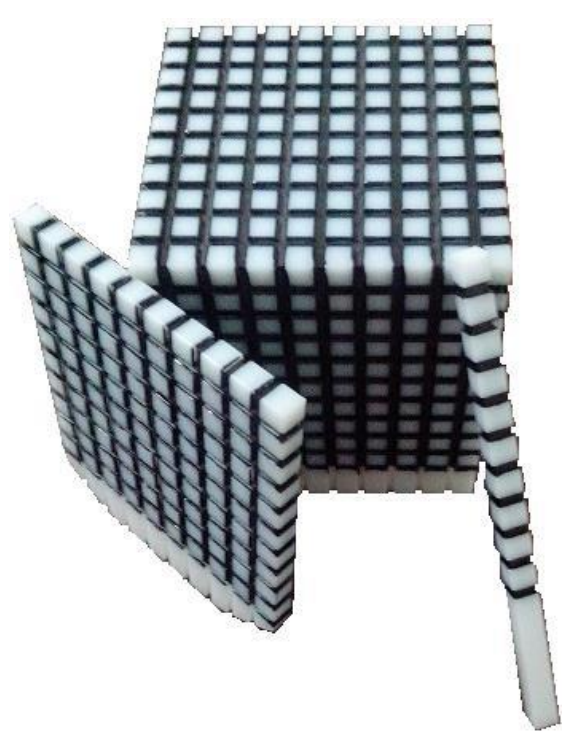

Figura 3 - Blocos com pintura nas ranhuras

Fonte: Marques (2015, p. 46)

Softwares desenvolvidos para sistemas embarcados são comumente denominados de firmware, normalmente executando em "bare metal", ou seja, sem Sistema Operacional. Este tipo de implementação possui a característica de obter o máximo desempenho do hardware, pois, o processador não precisa desprender tempo com tarefas dedicadas ao Sistema Operacional. No entanto, exige da parte do desenvolvedor o conhecimento mais aprofundado do Hardware e do sistema em geral. Neste trabalho o firmware desenvolvido para a placa de controle dos motores foi o elemento que requereu maior esforço em termos de implementação, pois todos os periféricos, UART, Timers, configurações de GPIOs e inicializações tiveram de ser realizadas na implementação, tais configurações são realizadas em registradores de funções específicas, que são blocos especiais de memória podendo ser de entrada, saída ou ambos e que são responsáveis pelas funções de controle e acionamentos do microcontrolador.

Um dos requisitos para a Contátil foi de representar os valores numéricos de forma tátil e audível, visto que para o deficiente visual estes dois sentidos são os principais substitutos da visão. Os áudios dos números foram então gravados no formato "mp3", sendo que, para números mistos, por exemplo: (quinhentos e cinquenta e dois), uma combinação de áudios é realizada para formar o valor necessário. Para fosse possível executar os trechos de áudio em um ambiente limitado, foi necessário utilizar um player de $\mathrm{mp} 3$ com baixo consumo de recursos do sistema e que possui a característica de ser executado por linha de comando do Linux, recebendo o arquivo de áudio como parâmetro, assim, optou-se por utilizar o player "mpg123" que atendeu a estes requisitos.

\section{VALIDAÇÃO DA CONTÁTIL}

A validação contou com a entrevista/interação de 19 professores, todos com experiência no ensino de Matemática para alunos deficientes visuais. Compondo assim um grupo de 7 licenciados em Matemática e 10 graduados em diferentes áreas do conhecimento, sendo que a grande maioria com formação em licenciatura em Pedagogia.

$\mathrm{Na}$ escolha dos sujeitos, além da experiência de docência com alunos deficientes visuais, contamos com seis professores cegos, que além de contribuir com sua prática pedagógica, possuem uma vivência e compreensão do que é enxergar com os demais sentidos e não com os olhos. 
As entrevistas/interações com o equipamento, tiveram duração entre 45 minutos à $1 \mathrm{~h}$ e 30 minutos, foram gravadas e avaliadas para que, a partir das conclusões críticas e sugestões, alterações de estrutura conceitos, e interfaces pudessem ser realizadas na Contátil, gerando assim subsídios para um equipamento melhor e mais eficiente para o que se propôs.

O primeiro contato dos entrevistados foi feito com a TA desligada, com o intuito de gerar curiosidade sobre o funcionamento do equipamento, um professor vidente expõe:

Antes de estar funcionando fiquei imaginando o que faria, sei lá o que pensei. Mas nem imaginei, achei muito legal, fiquei na expectativa, porque quando tu faz a pergunta que número é esse, primeiro vem na mente e depois na visão. Só que o deficiente nunca viu, não sabe, eu estou impressionada com a ideia que tiveram!

Com um dos professores cegos foi realizada a experiência de não utilizar o áudio, para validar a eficiência da representação dos blocos táteis, ao representar o valor 250 na Contátil, o mesmo desferiu o seguinte comentário enquanto tateava os blocos:

250. É eu entendi a dinâmica, subiu exatamente 200 porque aqui tem 100, aqui embaixo tem mais 100 (mostrando a centena), aqui subiram as 5 dezenas e claro que eu já tinha visto que aqui são 10 e aqui (mostrando a unidade) não tem nada. É possível tranquilamente, conhecendo a dinâmica da caixa ele identifica.

O resultado positivo na avaliação da Contátil pode ser percebido através da constatação da possibilidade de assimilação das grandezas representadas posicionalmente, sendo este o tema do seguinte comentário, feito por um professor com licenciatura em Matemática:

É interessante, ele sobe um por um, isso é importante para o aluno saber que está subindo agora é a centena, depois as dezenas e agora as unidades. O primeiro que ele sobe é a centena, depois as dezenas e por último as unidades.

Um professor que trabalha a 8 anos na área, classifica a TA como altamente didática, e menciona sua importância para o aluno cego:

É muito legal isso aqui, é muito bacana, é o concreto. Eu sinceramente acho que é muito didático para um aluno cego, porque um aluno vidente já requer muita atenção, um aluno cego, mais ainda, eu acho que vem justamente nesse sentido que ele terem uma coisa deles, terem essa percepção, algo diferenciado. Sabe qual é a sensação que eu tenho? Que é um livro didático para eles, porque é deles. Eles não têm isso, então a Caixa vem como um brinquedo, que eles irão trabalhar. É diferente de só escutar no computador, aqui eles têm o manuseio, tem a percepção com as mãos.

A exatidão do valor representado também foi ressaltada por um pedagogo alfabetizador que comenta sobre o Material Dourado:

Exato! Não tem como ele pegar mais unidades como pode acontecer no material dourado, pegar seis e achar que é cinco, aqui é fixo. Que legal! (quando estava subindo os valores). Com certeza, bem tranquilo para trabalhar com a alfabetização numérica.

Apresentamos uma frase de um dos professores ao interagir com a Contátil solicitando o valor 555:
Quando a gente trabalha o material dourado com eles, eles conhecem isso aqui (mostrando a centena) em separado, aqui eles terão a oportunidade de no concreto mesmo no número, cem, duzentos, trezentos, quatrocentos, quinhentos (contando as centenas), dez, vinte, trinta, quarenta, cinquenta (contando as dezenas), um, dois, três, quatro, cinco, show! Eles têm condições de sozinhos chegar a essas conclusões. Os vincos estão bem marcados e as peças sobrepostas com a delimitação adequada. É bem tranquilo os vincos, sim, ô! Perfeito, eles podem contar aqui no quadrado $e$ ver que tem 10 na coluna e 10 na linha, são 100, descendo estão sobrepostas, bem tranquilo para entender. Perfeito!

Algumas limitações foram salientadas pelos entrevistados, como:

- Tamanho e peso demasiadamente grandes (com ressalvas, pois a mesma característica foi elogiada por uma parte dos avaliadores).

- Por não ser um equipamento portátil, possível de se carregar na mochila.

- A Calculadora Tátil poderia deixar de fazer o aluno pensar no cálculo.

- O barulho. 
Este trabalho foi desenvolvido com o intuito de gerar uma Tecnologia Assistiva no ensino de Matemática básica capaz de auxiliar o aluno na formação dos conceitos das quantidades numéricas, valor posicional dos números, e operações fundamentais sobre números naturais. Sendo assim, a etapa de validação com os professores especialistas serviu para avaliar a Contátil como TA nos critérios de usabilidade, acessibilidade e eficiência, possibilitando aos entrevistados classificá-la como positiva ou negativa nestes quesitos.

Em um conceito geral a Contátil foi avaliada como sendo uma Tecnologia Assistiva que agrega valor ao ensino da Matemática, tendo recebido 18 conceitos positivos das 19 avaliações realizadas, como ilustra o gráfico da Figura 4. Segundo o único avaliador que conceituou negativamente a eficiência pedagógica da TA, o fato de o equipamento entregar uma resposta pronta ao ser digitado um valor numérico no teclado, faz com que o aluno deixe de pensar, tornando o aprendizado menos interativo, e sugeriu a utilização do material dourado tradicional em conjunto com a Contátil, o primeiro servindo para aquisição dos números e a última como reconhecimento dos conceitos aprendidos, certamente este tipo de feedback serve de inspiração para que novos protótipos sejam desenvolvidos baseados nos fundamentos didáticos e pedagógicos já consagrados.

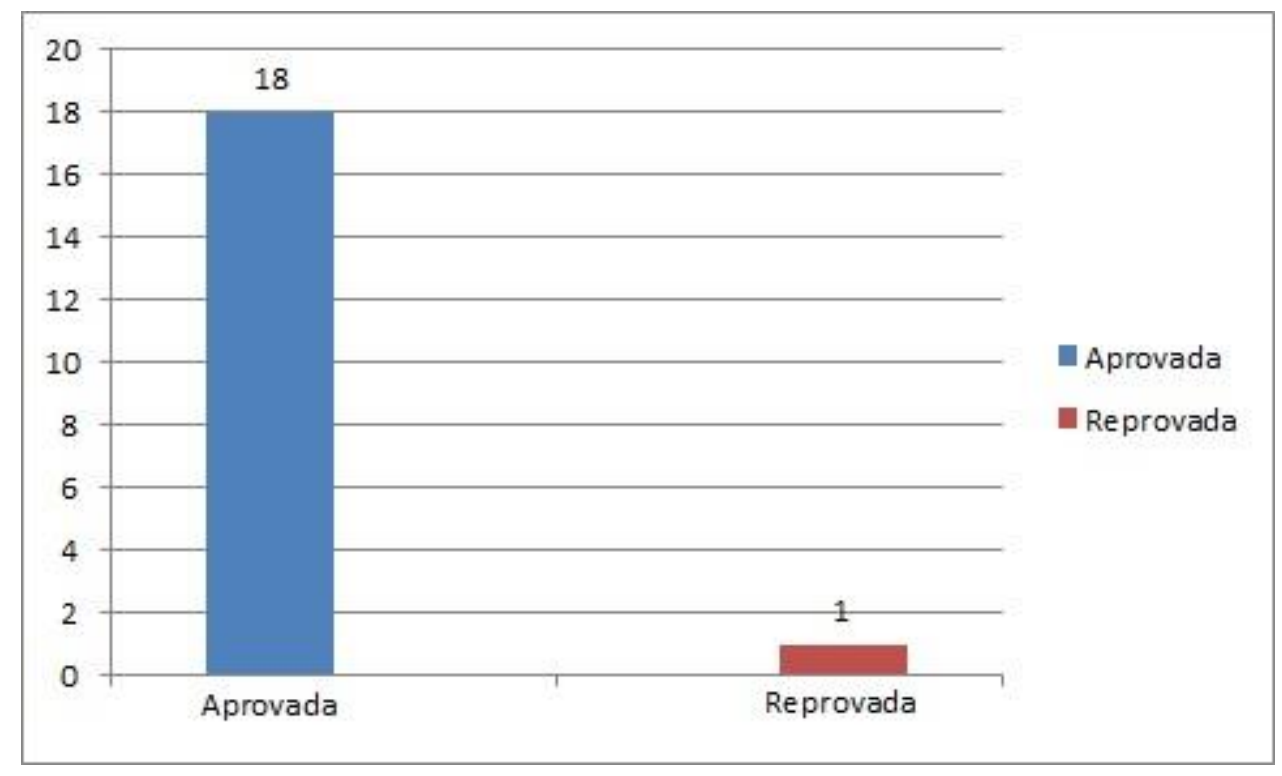

Figura 4 - Conceito Geral da Contátil

Fonte: Marques (2015, p. 56)

\section{CONSIDERAÇÕES FINAIS}

Apesar de crescente, a viabilização de ferramentas didáticas auxiliares no ensino de pessoas com deficiência ainda avança a passos curtos, ainda mais na área da Matemática, sendo essa uma área que demanda maior interesse por parte do governo, das instituições de ensino, do meio acadêmico e da própria população, que precisa desenvolver a mentalidade e práticas inclusivas na sua rotina.

A tecnologia tem se integrado cada vez mais naturalmente ao dia a dia das pessoas, e em suas mais variadas formas, são dispositivos e softwares que estão presentes no trabalho, nas casas, nas atividades de lazer, e até mesmo nas vestimentas dos indivíduos, assim, de igual forma a tecnologia tende a estar presente também no ensino, abrindo portas, como educação à distância, e se revelando como elemento renovador das metodologias de ensino largamente utilizadas nas instituições, assim, Tecnologias Assistivas também devem à medida do passar do 
tempo, se tornar mais comuns nas salas de aula, trazendo grandes ganhos na qualidade do aprendizado por parte do público ao qual são destinadas.

É importante ressaltar o elemento que norteou o desenvolvimento da Contátil, o Material Dourado, sendo este um inspirador, no formato e na ideia do produto, e que, mesmo tendo sido criado a mais de sessenta anos, ainda é presente nas salas de aula, figurando um elemento altamente promissor no ensino de matemática básica.

A Ferramenta desenvolvida neste trabalho foi fruto de estudos nas áreas de ensino especial e tecnologias variadas, em conjunto com parcerias desenvolvidas ao longo do projeto desde a sua concepção, sendo este, parte integrante de uma pesquisa de Mestrado (SGANZERLA, 2014) com continuação no Doutorado, além de receber contribuições significativas por parte de pessoas de diferentes áreas agregando assim valor ao resultado final do projeto, permitindo a participação no projeto de pesquisa "Tecnologias Assistivas para a Educação Matemática no Ensino Fundamental" aprovado no Edital Universal CNPq/MCTIC/SECIS No 20/2016, onde a mesma será reestruturada e reavaliada a partir das considerações dos participantes.

Infere-se assim, o valor educacional e a eficácia para o que se propôs o projeto da Contátil, tendo sido validado por uma equipe de professores com larga experiência no ensino de pessoas com deficiência visual.

\section{REFERÊNCIAS BIBLIOGRÁFICAS}

BERSCH, R.; MACHADO, R. Conhecendo o aluno com deficiência física. In: SCHIRMER, C. et al. Atendimento Educacional Especializado: deficiência física. Brasília: MEC/SEESP, 2007.

CONDE, A. J. M. Definindo a cegueira e a visão subnormal. 2005. Disponível em: <http://www.ibc.gov.br/images/conteudo/AREAS_ESPECIAIS/CEGUEIRA_E_BAIXA_VISAO/AR TIGOS/Def-de-cegueira-e-baixa-viso.pdf > . Acesso em: 08 set. 2014.

LIBÂNEO, J. C. et al. Educação escolar: políticas, estrutura e organização. 5.ed. São Paulo: Cortez, 2007.

MARQUES, C.M. Contátil: A matemática na ponta dos dedos. 2015. Monografia de conclusão de curso - Ciência da Computação. Universidade Luterana do Brasil, Gravataí, 2015.

NUNES, S.; LOMÔNACO, J.F.B. O aluno cego: preconceitos e potencialidades. Revista Semestral da Associação Brasileira de Psicologia Escolar e Educacional, SP. Volume 14, número 1, janeiro/junho de 2010.

RICHARDSON, M.; WALLACE, S. Primeiros passos com o Raspberry PI. São Paulo: Novatec, 2013.

SGANZERLA, M.A.R. Contátil: potencialidades de uma Tecnologia Assistiva para o ensino de conceitos básicos de matemática. 2014. 119 f. Dissertação (Mestrado) - Curso de Ensino de Ciências e Matemática, Programa de Pós-Graduação em Ensino de Ciências e Matemática, Universidade Luterana do Brasil, Canoas, 2014.

SILVA, M.; B. C, CAMPOS, I.; SÁ, E. Formação continuada a distância de professores para o Atendimento Educacional Especializado. Brasília: SEESP/ SEED/ MEC, 2007.

TESSEROLI, R. C; TUYAROT, D. E. Objetos educacionais digitais na EAD e educação inclusiva na área de física. RENOTE - Revista Novas Tecnologias na Educação, v. 14, n. 2, 2016. 